\title{
Child Labor and Development: An Introduction
}

\author{
Kaushik Basu and Zafiris Tzannatos
}

Long neglected by economists, child labor has experienced a sudden resurgence of interest as a subject of research and analysis since the mid-1990s. This is surprising at first glance, because the global incidence of child labor has been on the decline for several decades now. What accounts for the increased interest? One factor is the growing emphasis in the development literature on poverty reduction, particularly among the most vulnerable sections of the population, which includes children, especially working children. Simultaneously, with the heightened recognition of the importance of human capital accumulation as a catalyst-and perhaps even a prerequisite-for development, child labor is viewed as a major impediment to economic progress.

The recent academic interest is matched by the increasing prominence of child labor in both national and international policy settings. This is manifested in a series of international conventions, such as the U.N. Convention on the Rights of the Child (1989), the International Labour Organization (ILO) Convention 182 on Elimination of the Worst Forms of Child Labor (1999), and the U.N. Millennium Declaration (2000) with its emphasis on poverty reduction and universal education. These three documents share a common concern for banishing global poverty and investing in children.

This international concern, enshrined in various conventions, has been mirrored by economists' interest in globalization and its implications for poverty eradication. The new research has dimmed some of the earlier optimism that growth and globalization will automatically trickle down to the benefit of all. Child labor is a prime example. Though its incidence has declined, children continue to work in large numbers and for long hours, more so than should be tolerable in this age of globalization and prosperity. This persistent search for new, possibly specific solutions is now being facilitated by the increasing availability of micro data, which enable the explicit formulation and testing of critical propositions and policies. This should result in a more rigorous understanding of intrahousehold allocation mechanisms, their interaction with market forces, and the effect of these interactions on child labor.

The articles in this issue of the World Bank Economic Review make a small contribution to the growing debate on child labor. They are based on papers presented at an international conference, "The Economics of Child Labour" in Oslo in May 2002, sponsored by the ILO, the United Nations Children's Fund

DOI: $10.1093 /$ wber/lhg019

(C) 2003 The International Bank for Reconstruction and Development / THE WORLD BANK 
(UNICEF), and the World Bank and organized by Fafo, the Norwegian Institute for Applied International Research. The volume provides an overview of the issues (Kaushik Basu and Zafiris Tzannatos), gives a historical account of child labor (Jane Humphries), and presents the normative and philosophical conundrums that surround the problem of child labor (Debra Satz).

Four other articles consider various issues of direct policy or analytical relevance to developing economies, individually and on a cross-country basis. Sonia Bhalotra and Chris Heady analyze the paradoxical result that (with some qualifications) child labor tends to be more frequent in wealthier rural families of Ghana and Pakistan and examine the implications of this finding. François Bourguignon, Francisco Ferreira, and Phillippe Leite simulate the effect of the Brazilian schooling subsidy program Bolsa Escola and a set of alternative specifications of this kind of conditional cash transfer program on child labor, poverty, and education. Arnab Basu and Nancy Chau tackle the specific issue of child labor in situations of debt bondage, and Furio Rosati and Mariacristina Rossi try to explain the joint determination of school attendance and hours of work among rural children in Nicaragua and Pakistan. It is certainly more helpful to know the determinants of the hours of child labor rather than of child labor itself. Yet there was very little previous work on this topic.

A noteworthy feature of this volume is that its genesis lies in the increasing cooperation among international agencies. An aspect of this cooperation is the creation of a joint facility for data collection, sharing, and analysis, which enables researchers and policymakers to access a wealth of primary data and information on child labor across the globe. This issue concludes with a short note on the Understanding Children's Work project under the common auspices of ILO, UNICEF, and the World Bank.

We hope that the research presented in this volume and the increasing availability of statistical information will contribute to a better understanding of child labor and to its eventual demise. 